\title{
Ciclos de atenção a dietas da moda e tendências de busca na internet pelo Google trends
}

\author{
Cycles of attention to fad diets and internet search trends by \\ Google trends
}

Jasilaine Andrade Passos (https://orcid.org/0000-0001-9595-7822) ${ }^{1}$

Paulo Roberto Vasconcellos-Silva (https://orcid.org/0000-0003-4646-3580) ${ }^{2}$

Ligia Amparo da Silva Santos (https://orcid.org/0000-0002-6925-6421) ${ }^{3}$
${ }^{1}$ Escola Nacional de Saude Publica, Fiocruz. R. Leopoldo Bulhões 1480, Manguinhos. 21041-210 Rio de Janeiro RJ Brasil. jasilainepassos@ yahoo.com.br

${ }^{2}$ Instituto Nacional de Câncer. Rio de Janeiro RJ Brasil.

${ }^{3}$ Departamento Ciências da Nutrição, Universidade Federal da Bahia. Salvador BA Brasil.

\begin{abstract}
This work aimed at identifying, describing and analyzing news content associated with Google search cycles linked to eight types of diet: ketogenic; moon; protein; soup; detox; points; paleo; and Dukan. They were selected because they were pointed out by Google Trends ${ }^{\circledR}$ (GT) as the most often associated with the term "diet". The content of sites linked to the highest search peaks was pointed out by Google News ${ }^{\circledR}$. The volume of search attempts for diets was estimated by the GT with region filters (Brazil) and theme (Health) considering the period from 01/01/2012 to 01/01/2017. Results: hits portray ephemeral cycles, with hundreds of peaks and declining interest in the eight fad diets. The emphasis is on guidelines for quick weight loss in favor of optimal health as a proxy for an esthetic ideal. The scale of the risks associated with the more restrictive diets is often quoted and validated by expert information. The exposure and influence of the opinion of celebrities reporting their dietary experiences stand out. Contrary to the ideal of moderation, variety, and balance, fad diets portray the pressure for food self-control as a resource for building an idealized body typified by celebrity images.

Key words Fad diets, Social media, Consumer health information, Internet
\end{abstract}

Resumo Este trabalho objetivou descrever e analisar conteúdos de notícias associadas a ciclos de buscas ao Google ligados a 8 tipos de dieta: a cetogênica; da lua; da proteína; da sopa; detox; dos pontos; paleo; e Dukan. Estas foram selecionadas por terem sido apontadas pelo Google Trends ${ }^{\circledR}$ (GT) como as mais frequentemente associadas ao termo dieta. Os conteúdos dos sites vinculados aos maiores picos de buscas foram apontados pelo Google News ${ }^{\circledR}$. O volume de buscas às dietas foram estimados pelo GT com filtros de região (Brasil) e temática (Saúde) considerando o período de 01/01/2012 a 01/01/2017. Os acessos retratam ciclos efêmeros com centenas de picos e quedas de interesse pelas 8 dietas da moda. A ênfase se concentra nas orientações para rápida perda de peso em prol de um ideal de saúde tido como proxy de um ideal estético. A dimensão dos riscos associados às dietas mais restritivas é citada frequentemente e validada por informações de especialistas. Destaca-se a exposição e a influência da opinião de celebridades relatando suas experiências dietéticas. Ao contrário do ideal de variedade e equilíbrio, as dietas da moda retratam a pressão pelo autocontrole alimentar como recurso à construção de um corpo idealizado e tipificado por imagens das celebridades.

Palavras-chave Dietas da moda, Mídias sociais, Informação de saúde ao consumidor, internet 


\section{Introdução}

A internet tornou-se uma fonte abundante e acessível de informações sobre saúde em meio às quais muitas questões sobre alimentação e nutrição têm sido colocadas em distintivo patamar de exposição e interesse ${ }^{1,2}$. O acesso à informação abundante parece conformar demandas e estabelecer lacunas no que concerne à ideia de alimentação saudável ${ }^{3}$ em vista da quantidade, diversidade e centralidade de determinados tipos de informação amplamente disponíveis ao consumo de especialistas, consumidores leigos e replicadores de conteúdos sobre saúde ${ }^{4}$. Nesse campo, informações sobre dietas - seja para emagrecimento, desintoxicação, controle de condições mórbidas ou propósito equivalente - preenchem de conteúdos centenas de milhares de sites que buscam atender a variadas modalidades de fruição ${ }^{5}$.

Nos últimos anos têm sido desenvolvidos algoritmos cada vez mais sofisticados para análise de tendências de busca por palavras e termos no Google, como proxy dos ciclos de interesse coletivo direcionados a determinadas matérias. $\mathrm{O}$ volume gigantesco de dados produzidos por buscas diárias geo-referenciadas (ou seja, buscas associadas a determinadas regiões) registrado pelo Google Trends (GT - https://www.google.com. br/trends) podem fornecer insights interessantes sobre o que, onde e quando (além de "associado a quê") se ligam as buscas de uma determinada população - termo já consagrado na literatura como seekingbehavior (comportamento de buscas $)^{6-12}$. Tendências de buscas podem - de forma simples, transparente e de baixo custo - "predizer o presente" de diversas formas e sob vários aspectos ao disponibilizar suporte à análise de fenômenos socioculturais raramente estudados por esses meios ${ }^{13-20}$. Diversos autores percebem que estimativas sobre o volume de buscas em questões de saúde pública parecem promissoras no que se refere a aspectos culturais relevantes à formulação de políticas públicas, complementando e ampliando a compreensão das bases de dados existentes ${ }^{21-26}$. Até recentemente, o estudo das oscilações de termos de busca era empregado unicamente pelos especialistas em marketing, com fins mercadológicos, a fim de identificar tendências de consumo de produtos em associações colaterais com elementos da cultura. No entanto, o assim categorizado "comportamento de buscas" tem também se mostrado útil no delineamento de séries temporais que indicam ciclos de interesse coletivo (CIC) impulsionados por modas, boa- tos, material jornalístico e, sobretudo, pelo comportamento de celebridades influenciadoras ${ }^{27-30}$. Embora de valor escasso na análise qualitativa de significados socialmente construídos, é sensível a influências ligadas a temas de interesse da saúde coletiva, no papel de marcadores de fenômenos culturais efêmeros e, portanto, subdimensiona$\operatorname{dos}^{31-35}$. Sendo assim, o presente trabalho teve como objetivo identificar, descrever e analisar conteúdos veiculados por notícias associadas a picos de interesse pelas dietas da moda, examinando o papel exercido por atores sociais sob o foco da mídia no consumo de informações nesse campo.

\section{Metodologia}

O Google Trends (GT) apresenta estimativas que permitem dimensionar tendências de buscas sobre temas de interesse discriminadas em delimitações geográficas (estados; países; ou a nível mundial); categorias temáticas (saúde; ciência; notícias; viagens entre outras) além de delimitações temporais (períodos específicos; últimos cinco anos; última semana etc.). Os algoritmos do GT normalizam dados a partir de um número total de buscas em determinada região/período em uma escala que oscila entre 0 (volume de buscas menor que $1 \%$ em relação ao pico de popularidade) e 100 (pico de acessos) apresentados como Volumes Relativos de Busca/s (VRB). Os VRB são, por definição, sempre menores que 100 (eixos Y dos gráficos) retratando buscas em valores relativos, comparáveis a volumes de acessos mais altos ao longo de um período. A representação em proporções corrige o número absoluto de buscas considerando um número oscilante de acessos à Internet em uma determinada região. A metodologia empregada pelo GT é detalhadamente descrita no seu website ${ }^{36}$ assim como em diversos outros trabalhos da literatura ${ }^{14,21-26}$.

As "dietas da moda" foram escolhidas com base em revisões bibliográficas e na literatura leiga, também considerando-se assuntos relacionados ao termo de pesquisa "dieta" pelo Google Trends. Na coleta de dados foi realizada uma busca "limpa" após apagamento dos dados de navegação e cookies que poderiam influenciar o histórico de buscas. Foram escolhidas as oito dietas de maior visibilidade, ou seja, as que retornaram com volume de dados suficiente à análise: dieta cetogênica; dieta da lua; dieta da proteína; dieta da sopa; dieta detox; dieta dos pontos; dieta dukan e dieta paleo (paleolítica). Foram selecio- 
nados termos de busca - em português brasileiro - que se referem especificamente a essas dietas nas formas de grafia que geraram os resultados mais volumosos (ex. para buscas sobre "dieta paleolítica" utilizou-se o termo "dieta paleo"), conforme usualmente descrito em outros trabalhos. Os ciclos de dietas foram pesquisados a partir das últimas 261semanas (de 01/Janeiro/2012 a 01/Janeiro/2017) com filtros de região (Brasil) e tópico do assunto (Saúde). Os dados foram importados como arquivos CSV (Comma-separatedvalues) para planilhas eletrônicas (MS Excel ${ }^{\circledR}$ ) e foram aí calculadas as médias anuais com desvios-padrão e linhas de tendência (Polinomiais de ordem 2). As curvas das dietas foram tabuladas em oito séries independentes, sabido que o GT produz resultados comparando curvas de acessos ao pico de maior popularidade - o que poderia subestimar as estimativas das dietas menos populares.

Foram também analisadas notícias (Quadro 1) relacionadas ao objeto de estudo. Para a seleção das matérias utilizou-se os mesmos termos de buscas usados para as dietas, sendo incluídas na pesquisa as quatro primeiras notícias apontadas no Google News ${ }^{\circledR}$ nos períodos de pico de buscas de cada dieta da moda; considerando-se também aquelas que precederam os picos de busca em até dois dias, totalizando 32 notícias.

A opção pelas ferramentas do Google se deu em função de suas possibilidades técnicas e de inovação na abordagem do objeto de estudo. Além disso, conforme apontado em pesquisas de ranking do Alexa ${ }^{37}$ - companhia prestadora de serviços de análise da Web - esse é o site mais acessado no Brasil e no mundo para busca de informações por meio de acessos diretos via Google.com.br ou Google.com.

\section{Resultados e discussão}

\section{Volume relativo de buscas das dietas e ciclos de atenção}

Os resultados mais evidentes - de certa forma comum a todas as dietas - apontam para a fugacidade de interesse, sem CICs sustentados por longos períodos (Figuras 1 a 8). Há numerosos picos de acesso a cada dieta que expressam o caráter efêmero do interesse (geralmente ligado ao emagrecimento) e não compromissado com uma hegemonia perene de atenções. De forma geral, os picos de atenção ocorrem, sobretudo, entre setembro e janeiro com eminência nos meses próximos aos finais de ano, o que poderia ser descrito como uma espécie de "efeito verão" ou "efeito festividades de final de ano".

A dieta cetogênica apresentou lenta ascensão da linha de tendência com dezenas de picos de busca esporádicos com maior concentração nos últimos meses de 2016 , entre a $247^{\mathrm{a}}$ e a $255^{\mathrm{a}}$ semana (Figura 1). Todas as matérias associadas a esses picos se referem ao propósito de emagrecimento. Essa dieta é categorizada como restritiva - rica em gorduras, pobre em carboidratos e minimamente adequada em proteínas $^{38}$ e foi descrita na década de 1920 como alternativa suplementar ao controle da epilepsia, sobretudo no tratamento das epilepsias de difícil controle da infância ${ }^{38-41}$.

Com relação à dieta da lua observou-se uma linha de tendência com leve declínio pontuado por picos de VRB esporádicos, sobretudo entre as $114^{\mathrm{a}}$ e $204^{\mathrm{a}}$ semanas e ao final de 2016 (Figura 2). A “dieta da lua” pressupõe a influência do ciclo lunar nos líquidos corporais e a necessidade de adequação do regime alimentar a cada mudança de fase - o que implica consumo exclusivo de sucos, sopas e líquidos por 24 horas em 4 dias por mês ${ }^{42}$ com promessa de perda mensal de 4 $\mathrm{kg}$. Além disso, as matérias indicam que deve-se "parar de comer quando se sentir saciada/o e não consumir mais nenhum alimento após as 18 horas. Nas fases minguantes, os praticantes devem "beber muita água para eliminar as toxinas" ${ }^{43}$. Todo modo, as orientações se mostram generalizantes, dificultando o atendimento às demandas individuais - o que se mostra como aspecto comum às demais dietas.

A dieta da proteína - embora com expressivos picos de VRBs ao redor da $44^{\mathrm{a}}$ semana (em 2012) - apresentou uma curva de tendência decrescente no decorrer dos anos (Figura 3). Assim como a cetogênica, essa modalidade restritiva de regime recomenda o consumo semi-irrestrito de alimentos como carnes gordurosas, manteiga e outros produtos lácteos, limitando apenas a ingestão de carboidratos a menos de $30 \mathrm{~g}$ por $\operatorname{dia}^{44}$. $\mathrm{O}$ emagrecimento estaria relacionado ao efeito termogênico do metabolismo proteico ${ }^{45}$ e à característica cetogênica dessa dieta ${ }^{44}$ - derivados dos pressupostos estabelecidos em 1970 pelo Dr. Atkins ${ }^{46}$ : enfática restrição de carboidratos e preconização de alta ingestão de proteínas. As matérias ligadas à dieta não apresentaram descrições específicas de sua composição, mas citam seus efeitos e possibilidades de variação:

Perdi $11 \mathrm{~kg}$ com a dieta da proteina. Fiz direitinho por três meses, até conseguir chegar aos $48 \mathrm{~kg}$ (ela tem $1,70 m)^{47}$. 


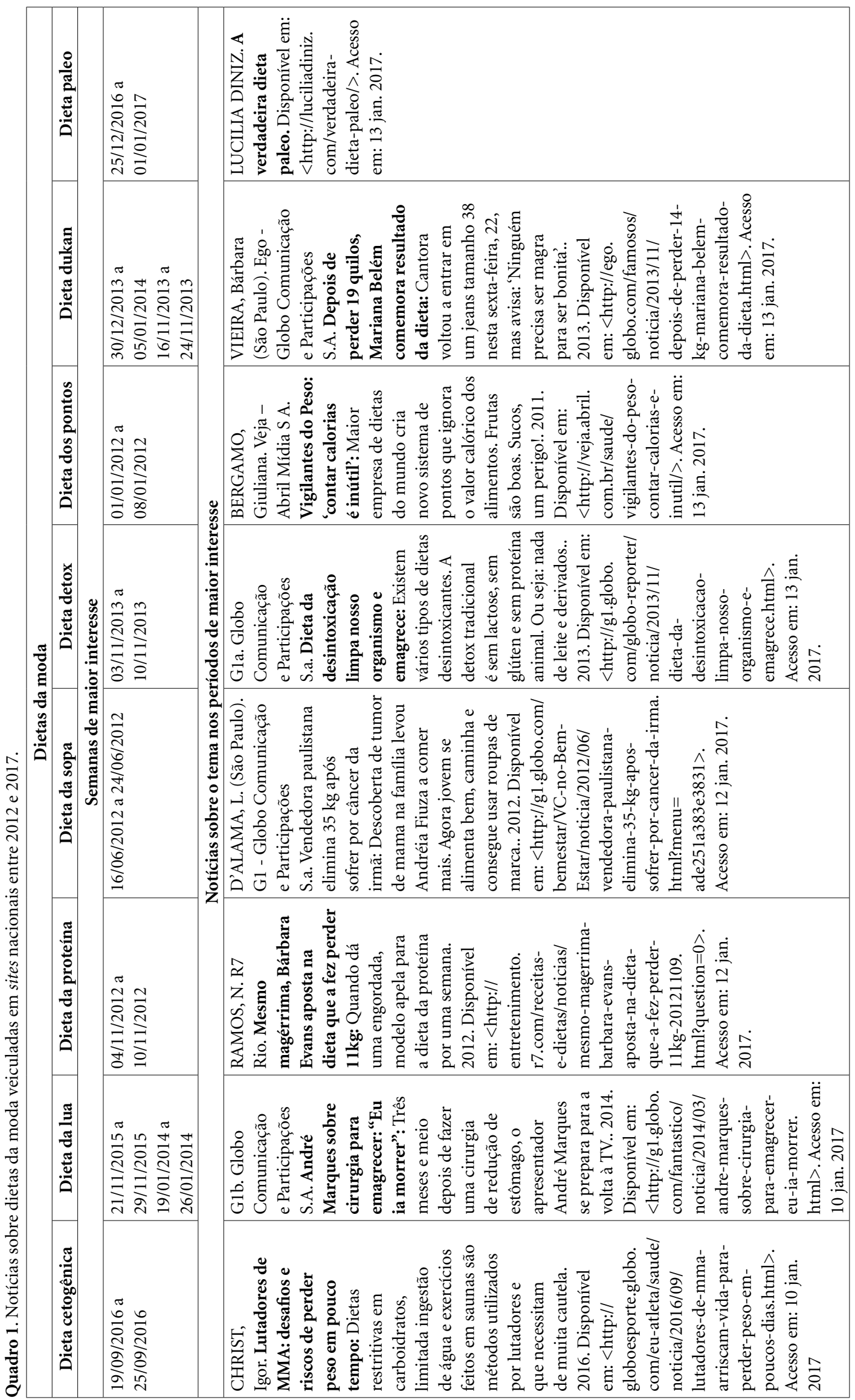




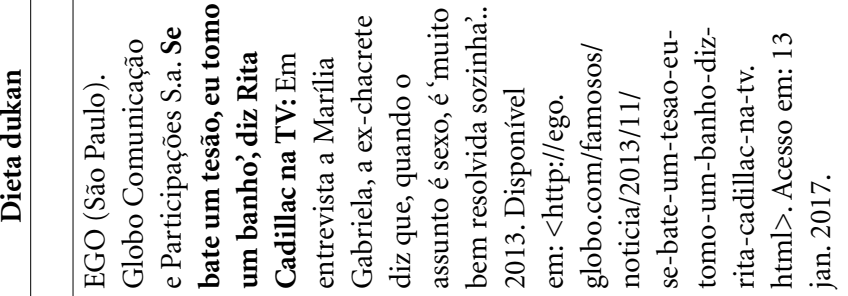

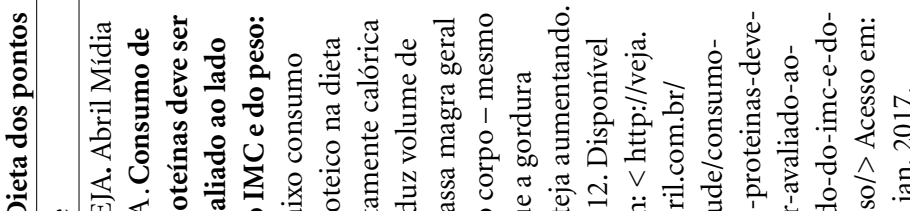

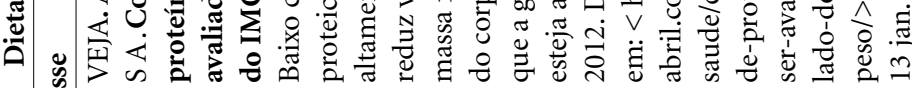

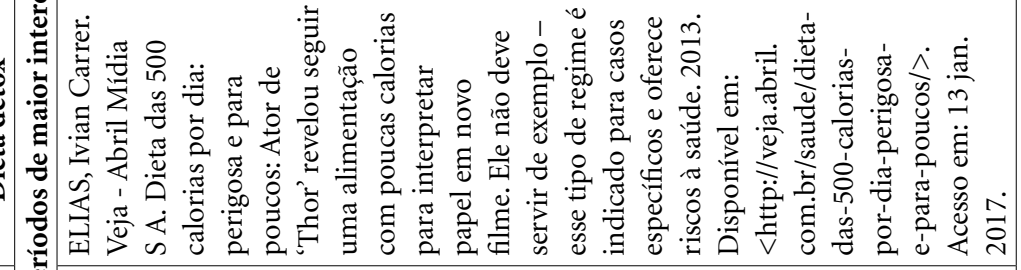

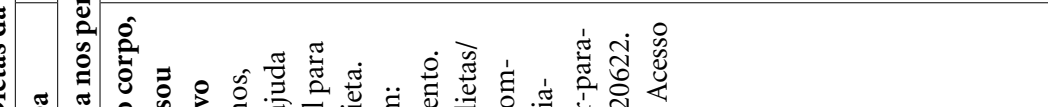




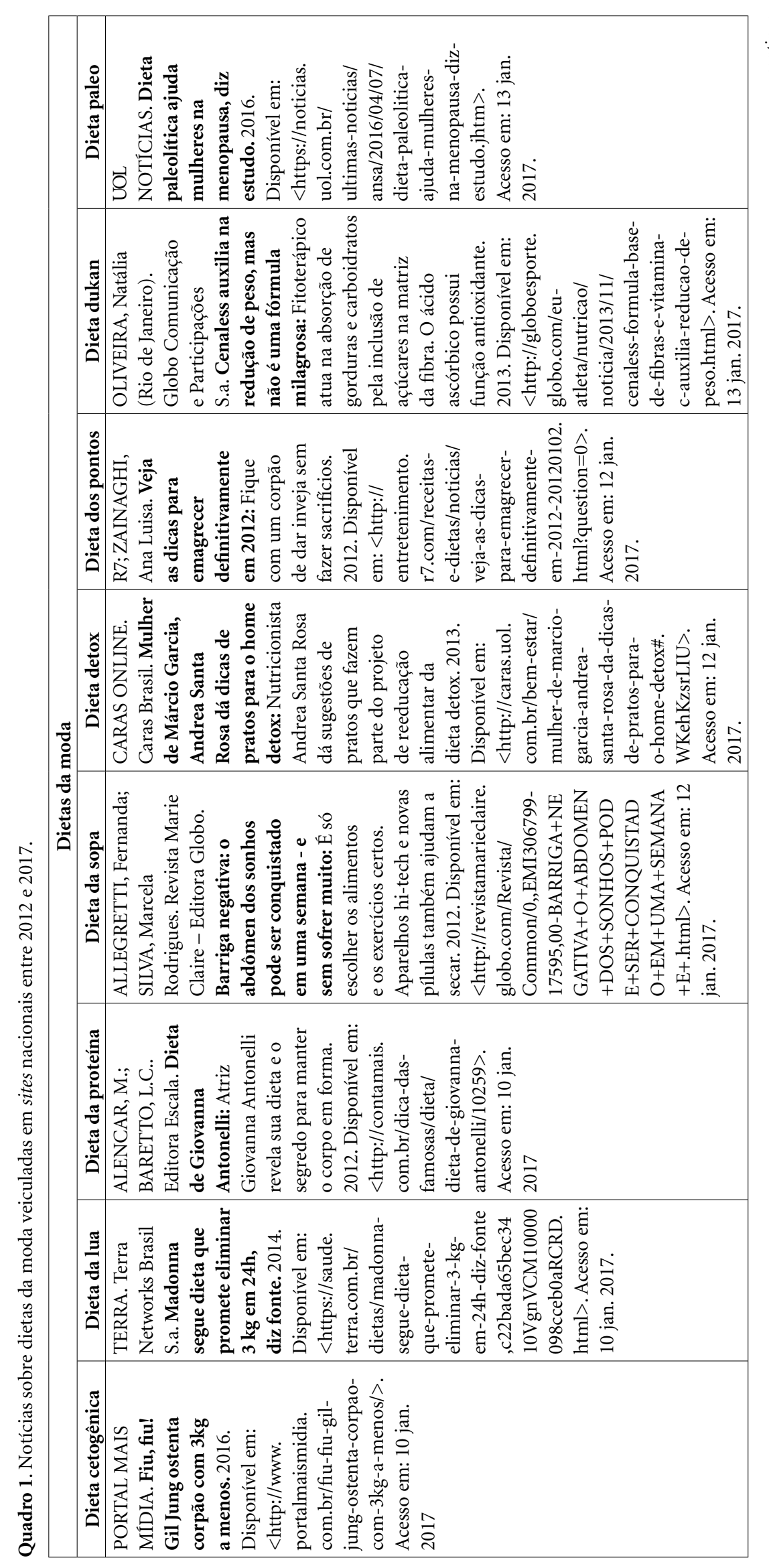




\begin{tabular}{|c|c|c|}
\hline & & 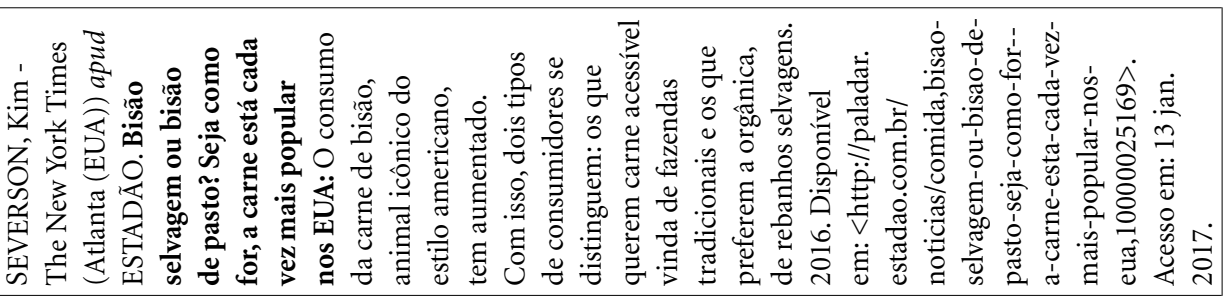 \\
\hline & & 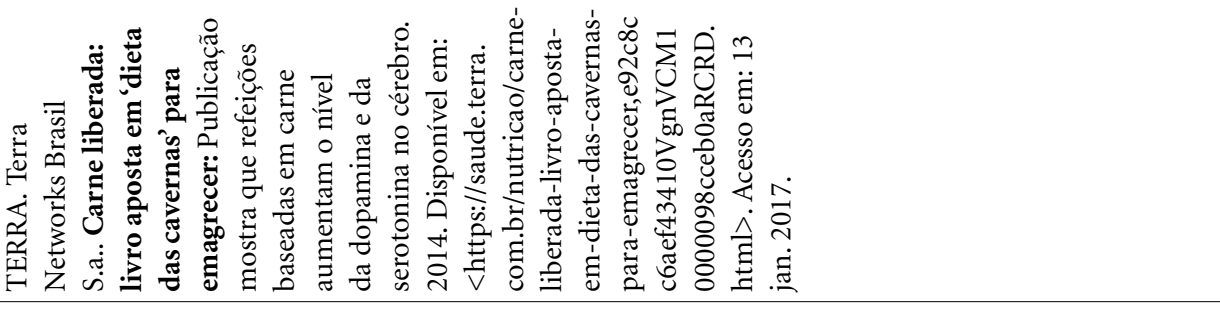 \\
\hline & & 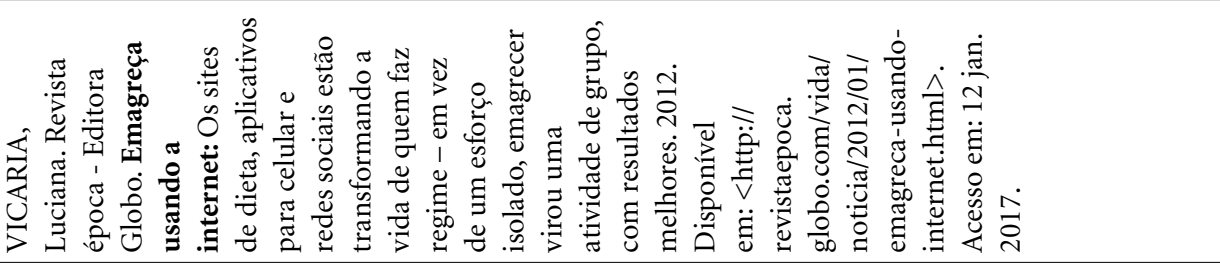 \\
\hline & & 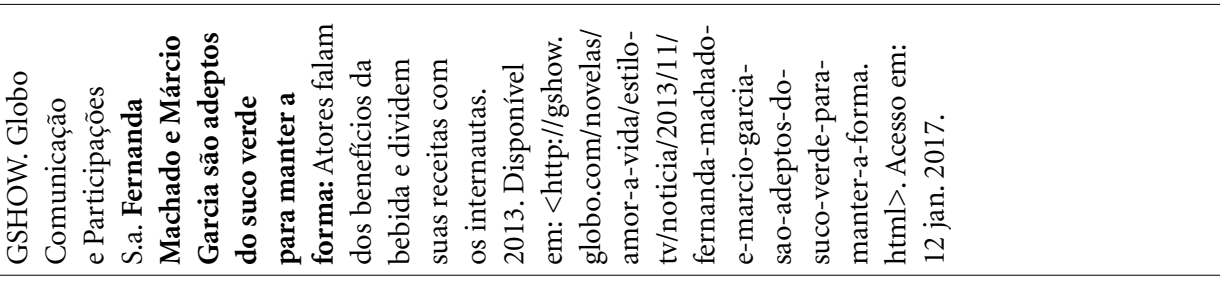 \\
\hline 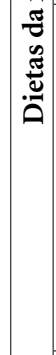 & & 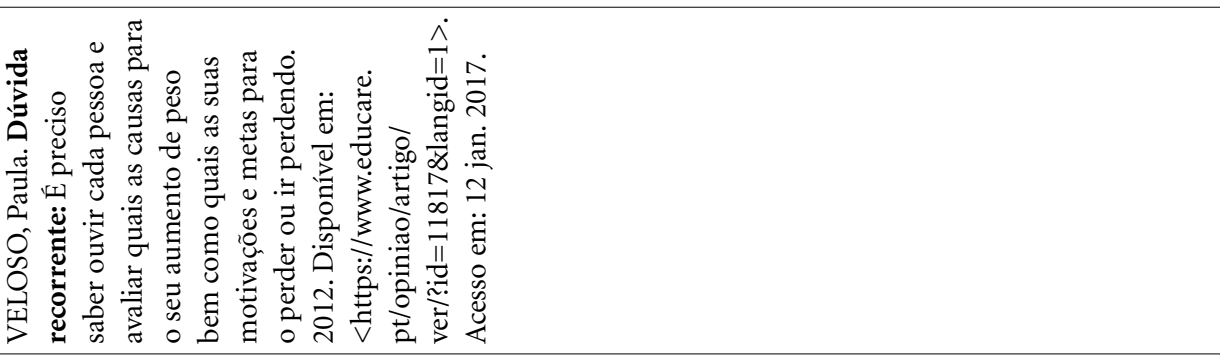 \\
\hline & & 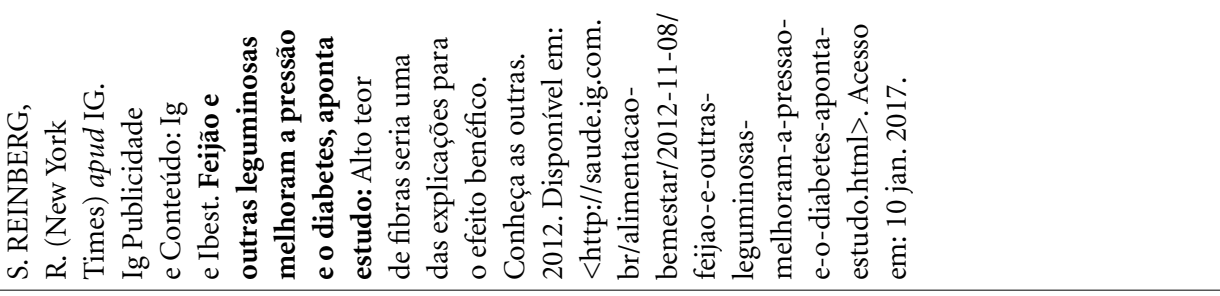 \\
\hline & & 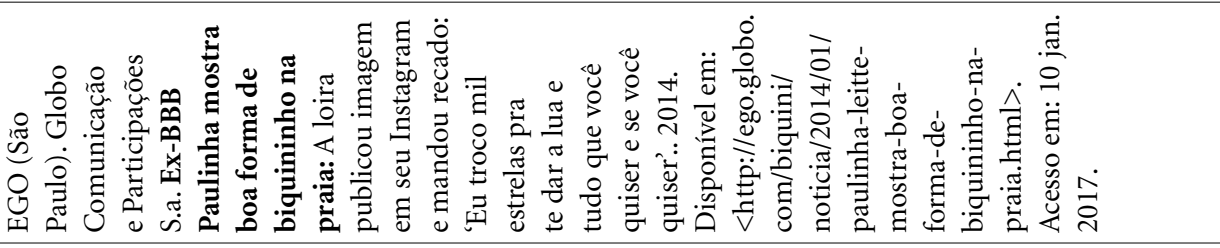 \\
\hline & & 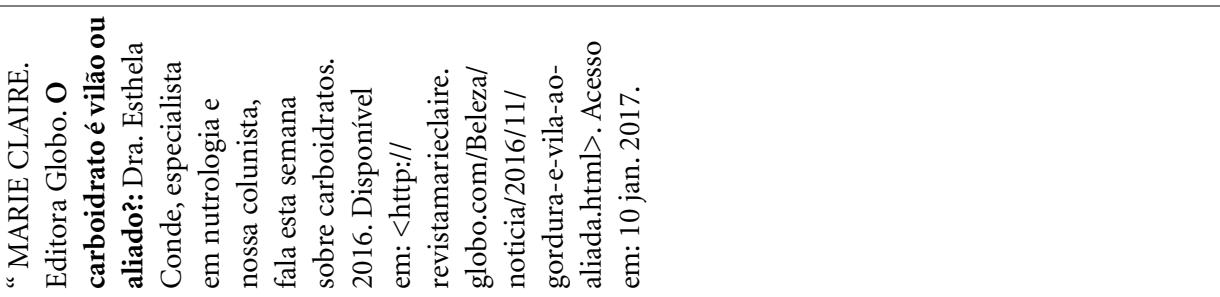 \\
\hline
\end{tabular}




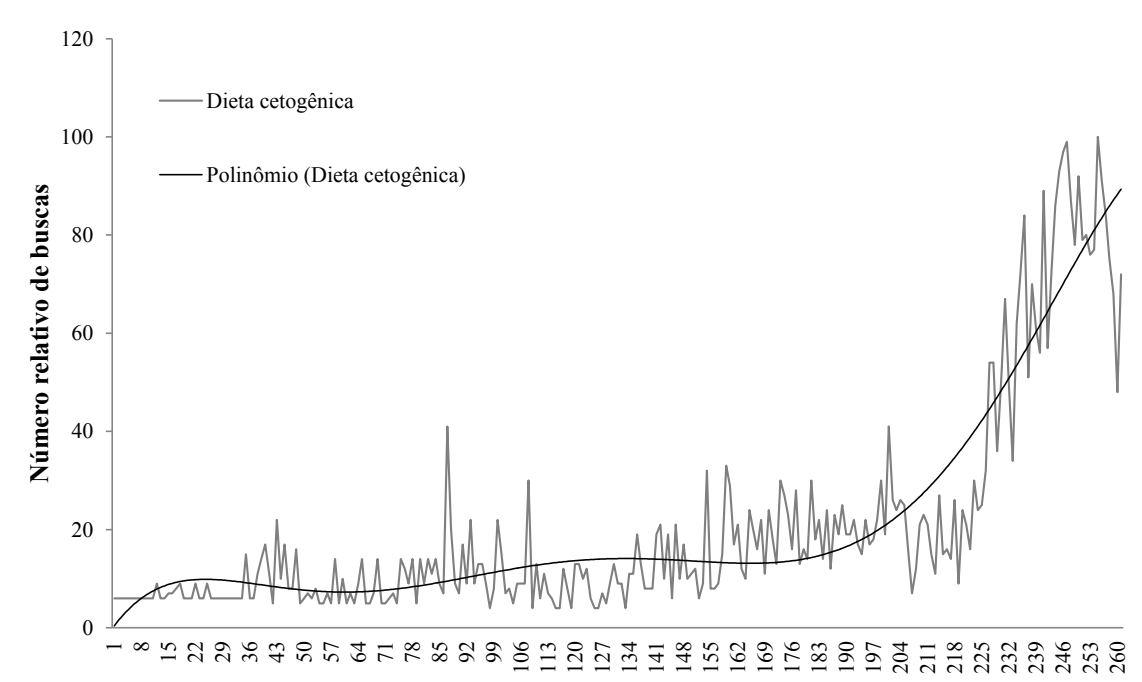

Semanas

Figura 1. Ciclos de atenção da dieta cetogênica.

Fonte: Google Trends, 2017.

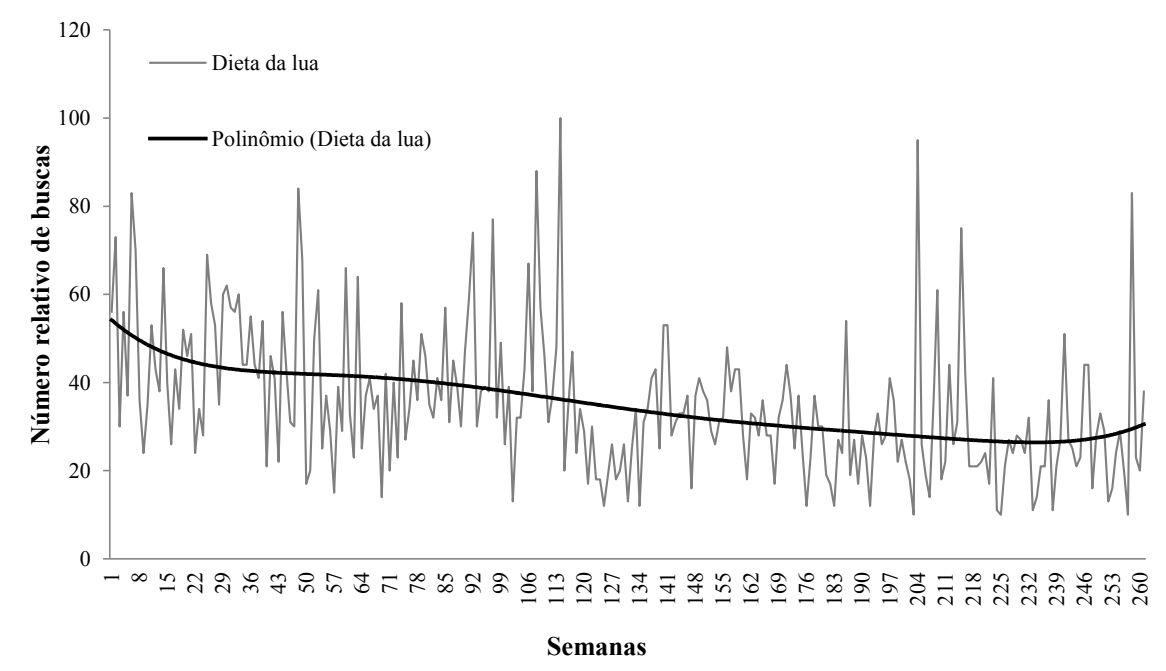

Figura 2. Ciclos de atenção da dieta da lua.

Fonte: Google Trends, 2017.

Bem menos radical do que a original criada pelo Dr. Atkins, a dieta das proteínas de alto valor biológico reduz a ingestão de carboidratos, em vez de aboli-los pura e simplesmente, assim como limita o consumo de gorduras, no lugar do passe livre $[. . .]^{48}$.

Nesse caso, é apresentada uma variação da dieta da proteína “original” (do Dr. Atkins) na 


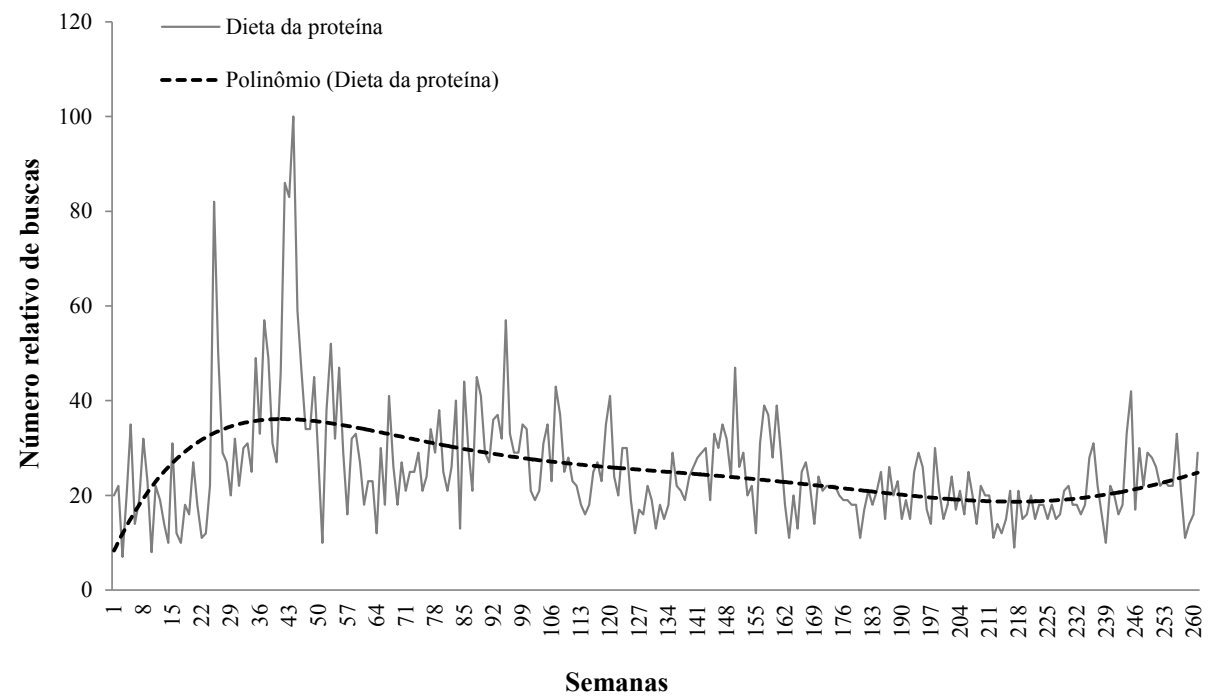

Figura 3. Cliclos de atenção da dieta da proteína (2012-2017).

Fonte: Google Trends, 2017.

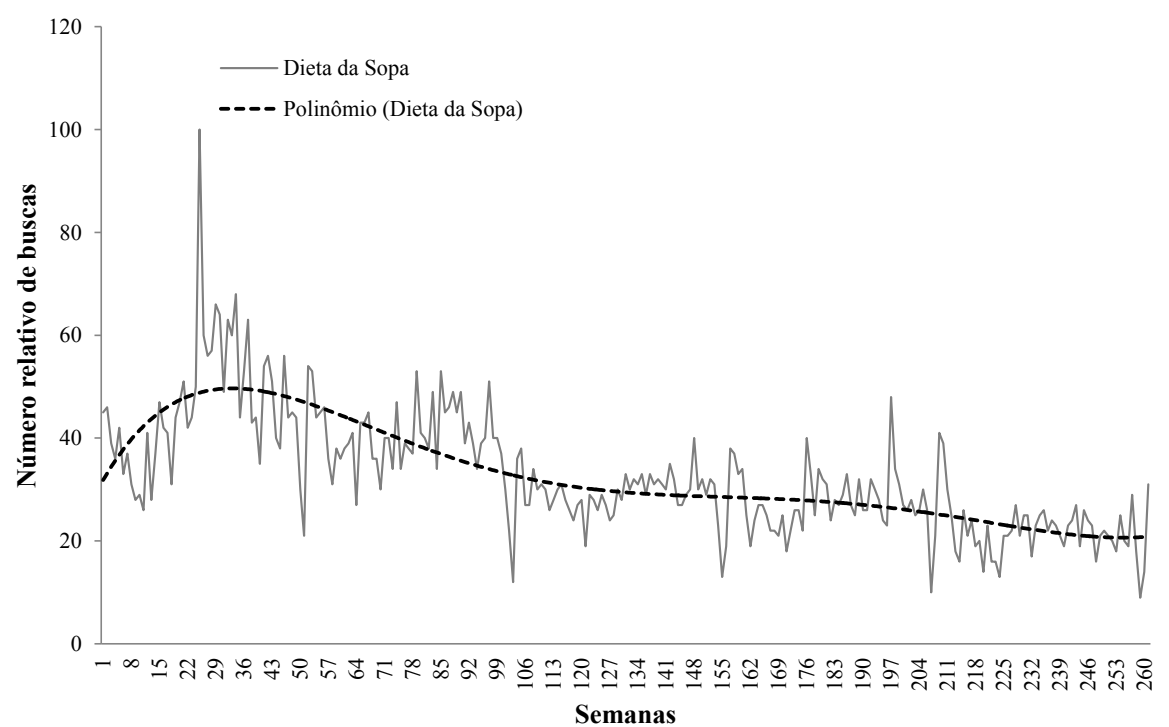

Figura 4. Ciclos de atenção da dieta da sopa.

Fonte: Google Trends, 2017.

qual se recomenda a preferência por proteínas de alto valor biológico e menor restrição de carboidratos na perspectiva de combater efeitos adversos da dieta clássica como "tontura, desânimo e lapsos de memória”48.
O interesse pela dieta da sopa (Figura 4) também se mostrou declinante na linha de tendência de seus ciclos de atenção após altos VRBs iniciais (acessos mais frequentes em 2012, na 25a semana). Os relatos apontados em sites indicam que 


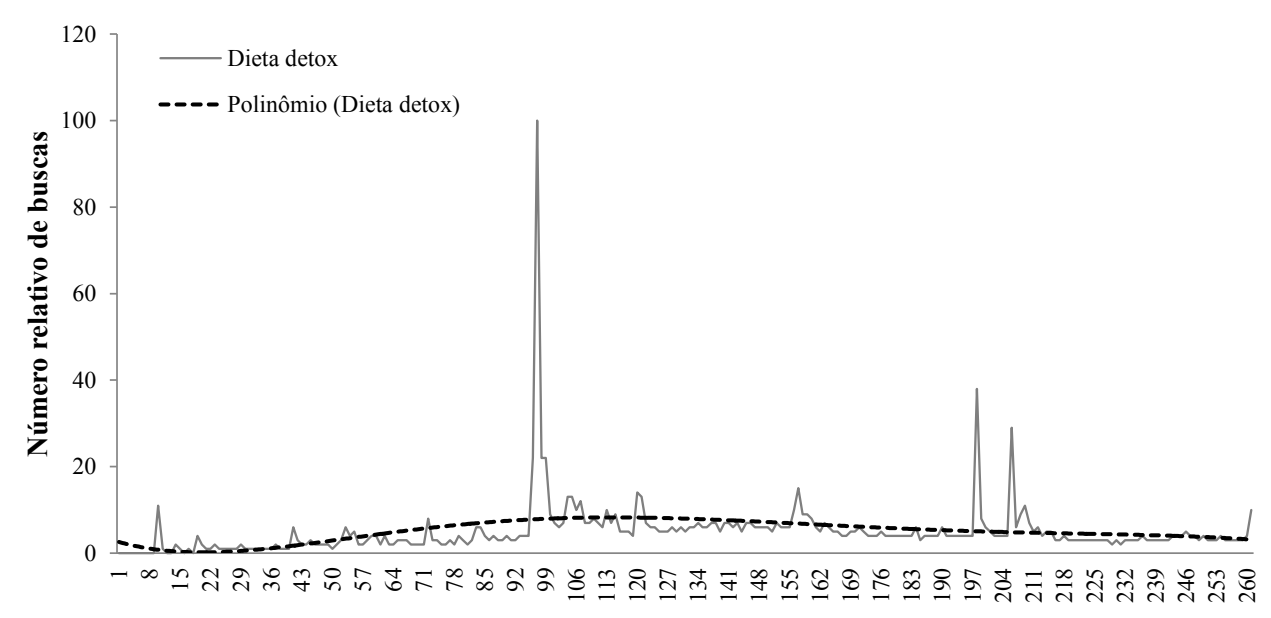

Semanas

Figura 5. Ciclos de atenção da dieta detox.

Fonte: Google Trends, 2017.

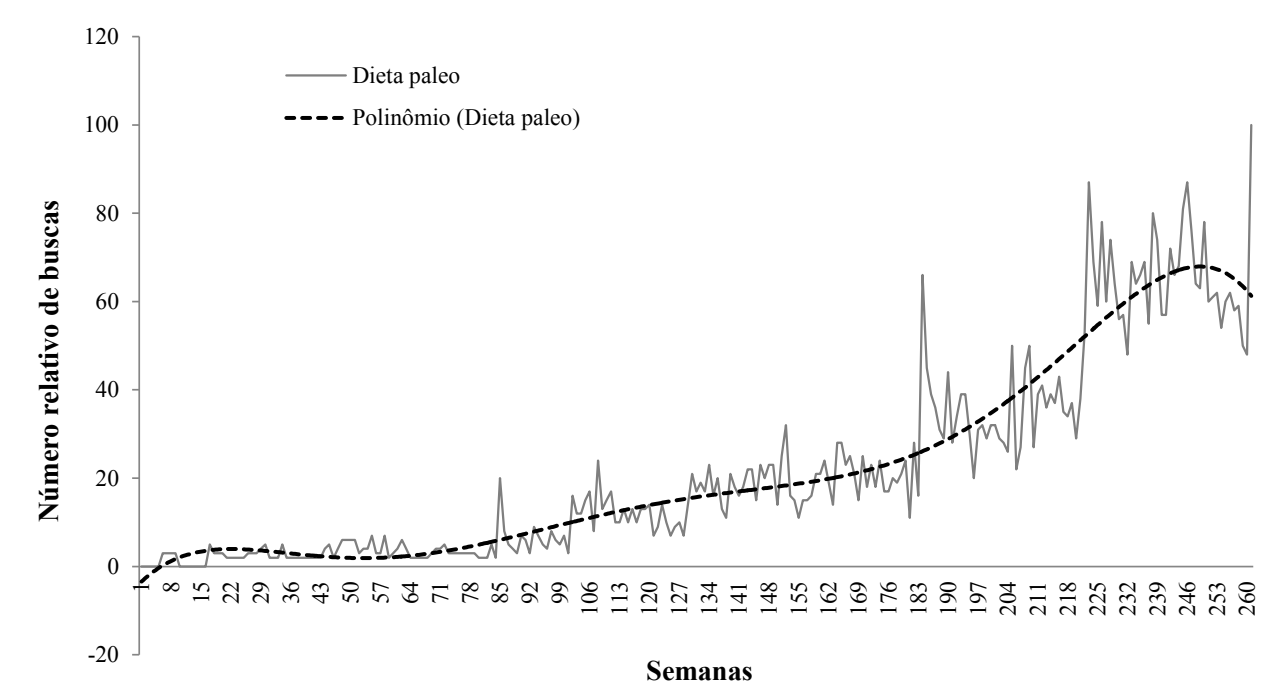

Figura 6. Ciclos de atenção da dieta paleo.

Fonte: Google Trends, 2017.

essa proposta dietética foi elaborada por pesquisadores da Universidade de São Paulo para pacientes com problemas cardíacos que precisavam perder peso para a realização de procedimentos cirúrgicos $^{49}$. Estudos feitos em populações asi- áticas e europeias evidenciaram relação entre o consumo de sopa e o menor risco de obesidade e sobrepeso, sugerindo que essa forma de dieta equilibrada pode trazer benefícios à saúde ${ }^{50,51}$. Preconiza-se o consumo de sopas pelo menos 


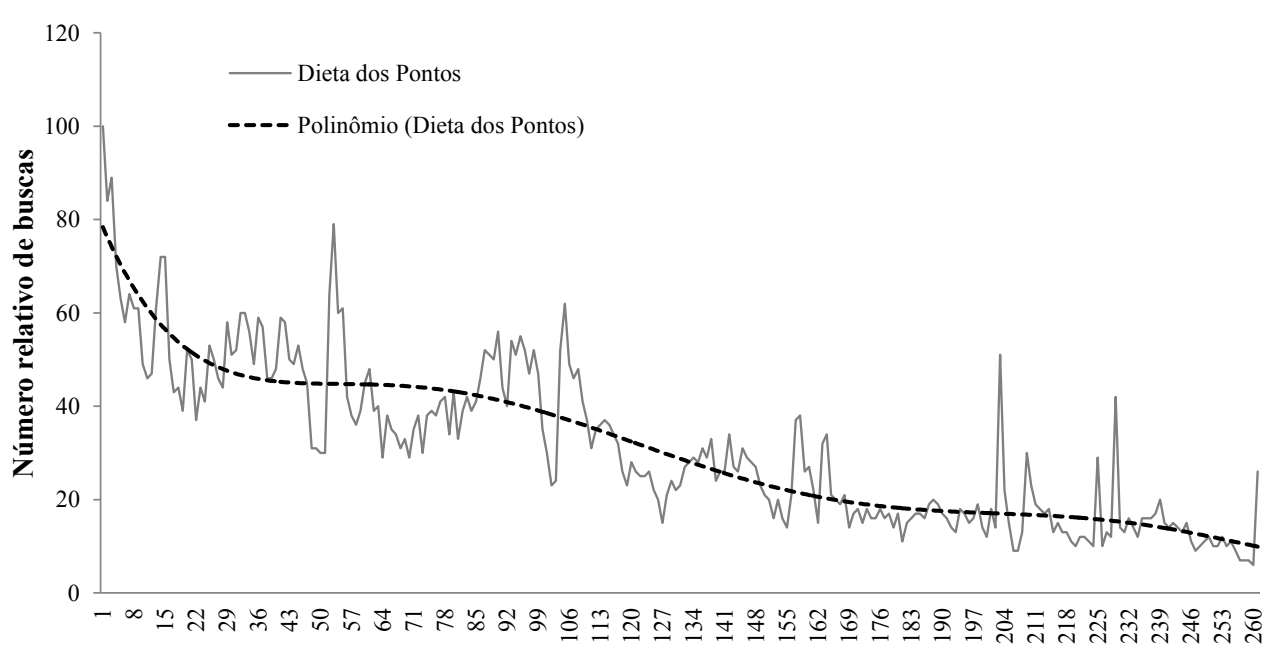

Semanas

Figura 7. Ciclos de atenção da dieta dos pontos.

Fonte: Google Trends, 2017.

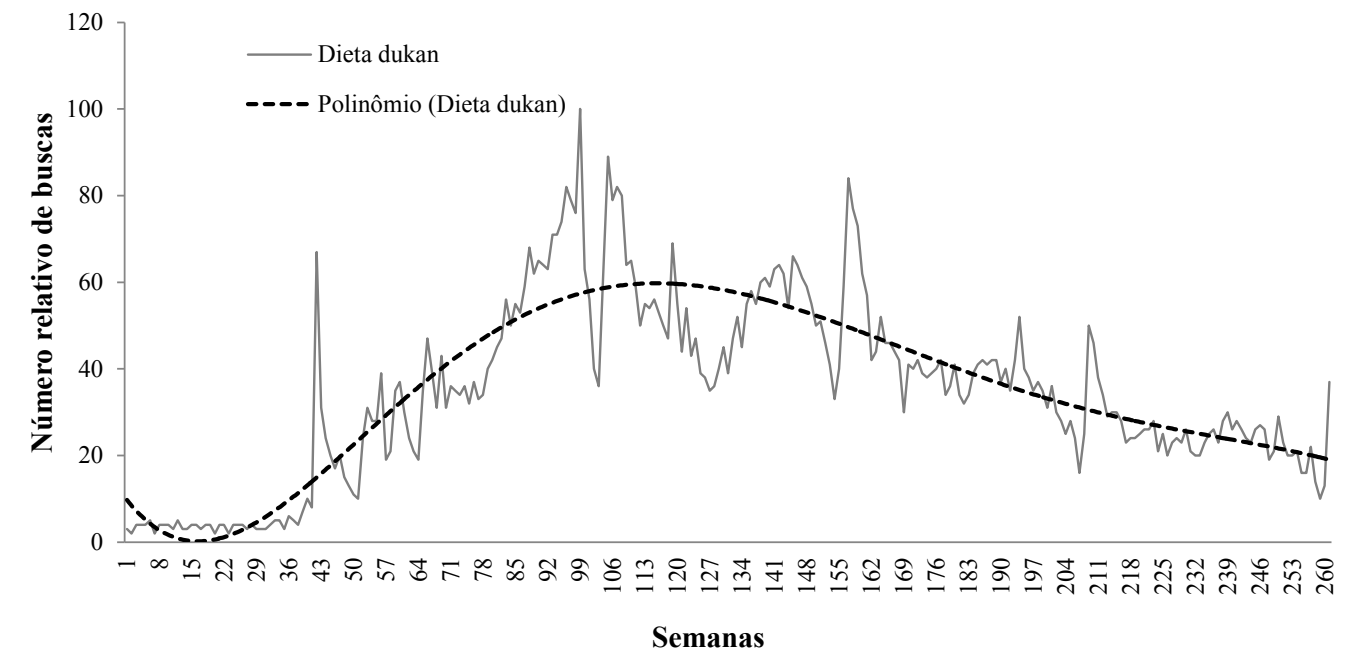

Figura 8. Ciclos de atenção da dieta Dukan.

Fonte: Google Trends, 2017.

2 vezes ao dia (especialmente almoço e jantar) por determinado intervalo de tempo ${ }^{49}$, no qual é aceitável o consumo de algumas frutas, legumes, carnes, sucos e chás sem açúcar ${ }^{49}$.
No que tange à dieta dos pontos, observouse declínio dos acessos com curva de tendência descendente a partir de expressivos picos iniciais (Figura 5). Essa dieta não restringe o consumo de 
alimentos e/ou nutrientes específicos desde que não seja ultrapassado o limite diário de pontos previamente estipulado ${ }^{52}$ que é atribuído a cada alimento. Quanto às definições disponíveis no ambiente virtual, temos: "A dieta dos pontos é uma dieta muito conhecida, por se poder comer o que quiser. Para quem faz dieta, saber que se pode fazer isso, ter vontade de comer e poder comer. É algo difícil de acreditar. A única coisa que não se permite é comer alimentos com gordura trans"53. Salienta-se que em um estudo realizado por Santana et al. ${ }^{54}$ a dieta dos pontos esteve dentre as mais frequentemente encontradas na internet.

Ao contrário das demais, a dieta detox despertou interesse concentrado em curtos períodos, sendo o mais expressivo na $97^{\text {a }}$ semana e mais dois nas 198 a e 206 a semanas (Figura 6). As "dietas detox" assumem práticas restritivas de curto prazo destinadas a eliminar toxinas do corpo com vistas à perda de peso e promoção de saúde ${ }^{55}$. Estratégias de desintoxicação existiram há milhares de anos em diferentes culturas e as orientações variam de jejum absoluto a dietas à base de $\operatorname{sucos}^{56}$.

A dieta Dukan, por sua vez, apresentou VRB inicialmente crescente entre as $78^{\text {a }}$ e $99^{\mathrm{a}}$ semanas embora, a partir daí verifica-se queda da linha de tendência com curtos picos esporádicos (Figura 7). Mesmo apresentando característica mais processual que outras dietas da moda, a dieta Dukan também prescreve baixa quantidade de carboidratos e alto valor protéic ${ }^{57,58}$. Teve origem a partir do método Dukan, que foi proposto pelo médico nutrólogo Pierre Dukan a partir de estudos realizados nos últimos $40 \operatorname{anos}^{59}$ e é baseada em quatro fases. A primeira fase (ataque) dura de 3 a 7 dias e consome-se apenas proteínas - sem restrição quantitativa. Há recomendação de ingestão de 2 litros de água e 20 minutos de caminhada. Na fase 2 (cruzeiro), além das recomendações da fase 1 acrescenta-se legumes e verduras ao cardápio e recomenda-se 30 minutos de caminhada. Na fase 3 (consolidação), com dez dias de duração, é permitido o consumo de proteínas, legumes, "duas frutas por dia, duas fatias de pão integral, $40 \mathrm{~g}$ de queijo, duas porções de carboidratos por semana, como massa, e duas refeições de gala por semana, onde é permitido uma entrada, um prato principal, uma sobremesa e uma bebida [...] a cada quilo é obrigatório fazer 25 minutos de caminhada" ${ }^{00}$ ). A fase 4 (estabilização) deve ser contínua - "dura o resto da vida e é possível comer normalmente" - desde que respeitadas três regras: consumir apenas proteína às quintas-feiras; fazer, no mínimo, 20 minutos de caminhada diariamente e usar escadas em detrimento de elevadores e consumir três colheres (sopa) de farelo de aveia ${ }^{60}$.

$\mathrm{Na}$ definição supracitada, especialmente por se conformar em um ritual com perspectivas de continuidade ao longo da vida, a dieta Dukan parece se aproximar de pressupostos da "reeducação alimentar". Além disso, apresenta clara associação da dieta com prescrição de atividade física regular - combinação tida como um dos pilares para a construção do corpo idealizado, conforme observado por Santos 5 .

A dieta paleo foi alvo de buscas crescentes nos últimos meses de 2016 com pico de interesse na última semana da série (Figura 8). A dieta paleolítica é uma referência ao modelo alimentar do homem dessa era, prescrevendo um padrão nutricional com base em plantas e animais selvagens consumidos há mais de 10.000 anos $^{61}$. Nesse caso, não haveria restrições relacionadas à proporção de macronutrientes, por exemplo, mas sim ao tipo de alimento. Recomenda-se evitar alimentos que não eram consumidos por nossos ancestrais, como: cereais (trigo, arroz, centeio, aveia, etc.); leguminosas (feijão, grão, lentilhas, etc.); lacticínios: (leite, iogurte, queijo, natas); gorduras: (óleo e margarinas vegetais) e produtos processados ${ }^{62}$.

Contradizendo alguns enunciados científicos que afirmam a insalubridade das dietas da moda, especialmente por serem restritivas ${ }^{63,64}$, a dieta paleolítica é citada em uma das matérias como fator de proteção para algumas enfermidades:

A dieta paleolitica pode trazer benefícios a longo prazo em problemas relacionados a obesidade, incluindo a redução do risco de diabetes e doenças cardiovasculares, explica a autora do estudo, Caroline Blomquist, da Universidade de Umea, Suécia ${ }^{65}$.

A principal restrição sinalizada é a ingestão de alimentos industrializados ou processados, o que estaria de acordo com orientações oficiais do Guia Alimentar para a População Brasileira ${ }^{66}$, por exemplo. Entretanto, ao contrário de recomendações do Guia, a matéria reforça o caráter controlador das "dietas" com a "proibição total" de determinado grupo de alimentos ao mesmo tempo em que traz a ideia de continuidade de tal regime alimentar "a longo prazo" para que seus benefícios sejam alcançados. 


\section{Dietas como risco, reeducação alimentar como credo e as celebridades}

Diferentemente da administração da dieta enquanto um procedimento terapêutico recomendado e baseado em evidencias científicas que o legitimam e, de algum modo, institucionalizam a tomada de decisão sobre a pertinência de seus usos, a escolha por dietas da moda geralmente assume caráter privado e abre espaço para a responsabilização do indivíduo.

Assim colocada a situação, cabe ao consumidor decidir sobre os pesos dos riscos e suas recompensas. "Viver... e gerenciar riscos" 67 se torna um preço exigido para acompanhar os valores da sociedade contemporânea (do risco, do espetáculo, do controle, de redes, da informação...) na qual o consumidor assume decisões sempre provisórias, enquanto aguarda novas informações a serem apropriadas, sobre novas dietas que surgem. Como descrito por Giddens, "na modernidade reflexiva as práticas sociais são constantemente examinadas e reformadas à luz de informação renovada sobre estas próprias práticas, alterando constitutivamente seu caráter"68.

Apesar de esforços para minimização dos "riscos", estes se mostram inerentes às dietas restritivas observadas no ambiente virtual. De modo geral, apresentando diferentes desenhos, as dietas da moda remetem para a necessidade do autocontrole e/ou autointerdição alimentar, pautada, principalmente, como forma de construção do corpo desejado.

Nas últimas décadas, a insatisfação com o corpo parece ter se ampliado sobremaneira, especialmente entre mulheres que aderem cegamente à abstenção restritiva de alimentos ${ }^{69}$. Tais práticas remetem a mecanismos de autocontrole imersos em um cenário no qual os discursos dietéticos e do marketing corporal exercem intensa influência na construção (por vezes, paradoxalmente, produzindo destruição) identitária dos sujeitos ${ }^{69}$. Para além da forma física do corpo, uma dieta saudável deveria contribuir para a construção simbólica do bem-estar dos sujeitos consigo mesmos - na construção reflexiva do corpo, busca-se aceitação social e a construção da própria felicida$\mathrm{de}^{5}$, entretanto as noções sobre alimentação saudável muitas vezes assumem aspectos normativos, essencialmente energético-quantitativos.

Autores $^{70,71}$ salientam que a compreensão das interfaces entre alimentação e saúde demanda análise de dimensões políticas, socioculturais e nutricionais que podem, inclusive, divergir sobre o que é considerado bom ou não para o corpo.
Contudo, na modernidade a racionalidade nutricional ganha destaque na elaboração de definições sobre alimentação saudável ainda que práticas correlatas estejam mais distantes do "mundo da vida"72.

A ideia de uma dieta como parte de um ritual provisório, como imperativo essencial à ascese para o corpo ideal, encontra seu contraste com o credo perene na reeducação alimentar - o que é vagamente presente em enunciados sobre dieta detox: O detox é para você fazer por um período determinado e depois entrar com uma reeducação alimentar [...] Existem vários tipos de dietas desintoxicantes. A detox tradicional é sem lactose, sem glúten e sem proteína animal ${ }^{33}$.

Com relação à dieta da lua, o Google News ${ }^{\circledR}$ apontou uma entrevista intitulada André Marques sobre cirurgia para emagrecer: Eu ia morrer ${ }^{74}$. Na matéria o apresentador (celebridade no cenário nacional) enumera suas tentativas mal sucedidas (entre elas a "dieta da lua") de emagrecimento antes da realização de uma cirurgia bariátrica: [...] eu tinha tentado todos os métodos possíveis e imaginários: ortomolecular, dieta da lua, copo d'água embaixo da pia. Remédio, tomei todos que você possa imaginar ${ }^{74}$. De modo geral, as matérias - sobretudo as que incitam à aderência aos ritos dietéticos, ou o consumo de produtos ou alimentos - frequentemente fazem referência a celebridades em seus títulos.

A experiência dos ícones culturais do corpo perfeito são frequentemente evocadas. Dentre as 32 notícias selecionadas, apenas 12 não faziam alusão direta às dietas de modelos, atores, atrizes, apresentadores, esportistas ou ex-participantes de reality shows. Apesar da disseminação de informações sobre saúde por meio de celebridades não ser necessariamente negativa, há outras variáveis a considerar. Segundo Rayner ${ }^{75}$, diversas celebridades australianas conseguem atenção da mídia por conta de experiências pessoais relacionadas a condições das quais foram vítimas. Nesse contexto, também conseguem o foco das atenções assumindo preocupações com a prevenção de males - e aproveitando o espaço para divulgação de produtos comercialmente potencializados pela condição de celebridade. De modo geral, a contribuição das celebridades nesse campo é alvo de discussão no cenário científico, especialmente no campo das intervenções públicas para prevenção de doenças ${ }^{76}$. A participação de pessoas famosas associada ao marketing de produtos está longe de ser considerada "promotora de saúde", pois acaba remetendo ao incentivo do consumo ${ }^{77}$.

Nos conteúdos tidos como mais especificamente direcionados à promoção da saúde per- 
cebe-se maior presença de resultados de estudos científicos e opiniões profissionais de saúde. Nesse quesito, é válido refletir sobre o modo como se dá a atuação profissional, uma vez que esses atores sociais podem fomentar o consumo de informações e serviços de saúde, que, a depender do seu grau de envolvimento nas práticas cotidianas, podem caracterizar a medicalização ${ }^{78}-$ processo pelo qual questões que não necessariamente são problemas médicos passam a ser tratados enquanto tal, geralmente interpretados como doenças ou desordens ${ }^{78}$.

No campo da Alimentação e Nutrição essa ideia pode ser traduzida pela supracitada "racionalidade nutricional"79: "práticas alimentares atentas ao permanente cuidado em manter na alimentação o equilíbrio de nutrientes, em detrimento do prazer de comer e dos valores com que a alimentação marca o convívio social a ele associado". Viana et al. ${ }^{79}$ situam a atuação do nutricionista como medicalizadora quando a esfera da prevenção é abandonada passando a intervenções dietéticas rígidas - sempre apoiadas pela mídia - que convertem o risco em quase-doença na administração da vida cotidiana por meio de normas sanitárias.

Em algumas matérias, a dimensão dos perigos em torno do alimento é evocada de forma sensacionalista; e também permitem observar o que é entendido por alguns autores como comoditização da ciência ${ }^{80}$ - fenômeno no qual o conhecimento científico, em meio aos jogos de poder, passa a ser utilizado em prol de interesses mercadológicos. Estando a serviço de uma perspectiva capitalista, a ciência estaria voltada para o desenvolvimento de produtos que atendam às necessidades de consumo ${ }^{79}$ de grupos sociais, sendo essas necessidades muitas vezes construídas a partir de estratégias de marketing econômico em meios nos quais produtos alimentícios podem ser facilmente observados.

\section{Considerações finais}

O Google Trends mostrou-se uma ferramenta relevante na análise de interesses sobre temas em saúde e uma alternativa para a realização de pesquisas no vasto campo de estudos que é a Internet.

Em meio à produção e ao consumo de informações sobre dietas da moda, a opinião de especialistas e a exposição das celebridades é reificada pelas dietas, que assumem similaridades e diferenças a partir das quais oscilam no vasto mercado simbólico da alimentação saudável. As novidades - sejam em formatos de regimes diferenciados, mudanças em intervalos das refeições ou alterações de equilíbrios dietéticos - se prestam a agregar valor simbólico eficaz em despertar o interesse dos internautas por acenos de emagrecimento rápido com saúde. O consumo desse tipo de informações reflete bem valores centrais à sociedade líquida descrita por Bauman ${ }^{81}$, pautada pelo consumismo e pela necessidade incessante e incoercível de gerar e suprir desejos. Revela o imediatismo de consumidores em busca do efêmero em meio aos ciclos mercadológicos aplicados pelo marketing digital, como AIDAs (Attention, Interest, Desire, Action) dietéticas, cujos produtos guiarão a novas buscas e novos desejos em sequencial geração.

Salienta-se a necessidade de estudos que investiguem junto aos consumidores repercussões desse consumo de informações via Internet nas suas vidas e práticas alimentares cotidianas. 


\section{Colaboradores}

JA Passos: Participou de todas as etapas de elaboração do manuscrito, desde a concepção do desenho de estudo, interpretação e análises de dados à revisão final. PR Vasconcellos-Silva: Participou da concepção do desenho de estudo do manuscrito, da análise crítica e da revisão final. LAS Santos: Participou da análise crítica e revisão final do manuscrito.

\section{Referências}

1. Beck F, Richard J-B, Nguyen-Thanh V, Montagni I, Parizot I, Renahy E. Use of the Internet as a Health Information Resource Among French Young Adults: Results From a Nationally Representative Survey. J Med Internet Res 2014; 16(5):e128.

2. Rangel-S ML, Lamego G, Gomes ALC. Alimentação saudável: acesso à informação via mapas de navegação na internet. Physis 2012; 22(3):919-39.

3. Santos LA . Educação alimentar e nutricional no contexto da promoção de práticas alimentares saudáveis. Rev Nutr 2005; 18(5):681-692.

4. Vasconcellos-Silva PR, Castiel LD, Bagrichevsky M, Griep RH. As novas tecnologias da informação e o consumismo em saúde. Cad Saude Publica 2010; 26(8):1473-1482.

5. Santos LA . Os programas de emagrecimento na Internet: um estudo exploratório. Physis 2007; 17(2):353372.

6. Abedi V, Mbaye M, Tsivgoulis G, Male S, Goyal N, Alexandrov AV, Zand R. Internet-based informationseeking behavior for transient ischemic attack. Int $J$ Stroke 2015; 10(8):1212-1216.

7. Brownstein JS, Freifeld CC, Madoff LC. Digital Disease Detection - Harnessing the Web for Public Health Surveillance. N Engl J Med 2009; 360(21):2153-2157.

8. Medlock S, Eslami S, Askari M, Arts DL, Sent D, de Rooij SE, Abu-Hanna A. Health Information-Seeking Behavior of Seniors Who Use the Internet: A Survey. J Med Internet Res 2015; 17(1):e10.

9. Pan S, Xu J-J, Han X-X, Zhang J, Hu Q-H, Chu Z-X, Hai Y-Q, Mao X, Yu Y-Q, Geng W-Q, Jiang Y-J, Shang H. Internet-Based Sex-Seeking Behavior Promotes HIV Infection Risk: A 6-Year Serial Cross-Sectional Survey to MSM in Shenyang, China. BioMed Res Int 2016; 2016:2860346.

10. Salwa B, Suha A, Maha A, Ma'an A, Khaled A, Mowafa $\mathrm{H}$. The Prevalence of Internet and Social Media Based Medication Information Seeking Behavior in Saudi Arabia. Stud Health Technol Inform 2016; 226:275278.

11. Soleymani M, Garivani A, Zare-Farashbandi F. The Effect of the Internet Addiction on the Informationseeking Behavior of the Postgraduate Students. Mater Socio Medica 2016; 28(3):191.

12. Vasconcellos-Silva PR, Castiel LD, Griep RH, Zanchetta M. Cancer prevention campaigns and Internet access: promoting health or disease? J Epidemiol Community Health 2008; 62(10):876-881.

13. Askitas N, Zimmermann KF. Google Econometrics and Unemployment Forecasting. Appl Econ Q 2009; 55(2):107-120.

14. Choi H, Varian H. Predicting the Present with Google Trends: predicting the present with Google Trends. Econ Rec 2012; 88(s1):2-9.

15. Cooper CP, Mallon KP, Leadbetter S, Pollack LA, Peipins LA. Cancer Internet Search Activity on a Major Search Engine, United States 2001-2003. J Med Internet Res 2005; 7(3):e36.

16. Ettredge M, Gerdes J, Karuga G. Using web-based search data to predict macroeconomic statistics. Commun ACM 2005; 48(11):87-92. 
17. Ginsberg J, Mohebbi MH, Patel RS, Brammer L, Smolinski MS, Brilliant L. Detecting influenza epidemics using search engine query data. Nature 2009; 457(7232):1012-1014.

18. Gunther E. Infodemiology: Tracking Flu-Related Searches on the Web for Syndromic Surveillance. AMIA Annu Symp Proc 2006; 2006:244-248.

19. Hulth A, Rydevik G, Linde A. Web Queries as a Source for Syndromic Surveillance. PLoS ONE 2009; 4(2):e4378.

20. Polgreen PM, Chen Y, Pennock DM, Nelson FD. Using Internet Searches for Influenza Surveillance. Clin Infect Dis 2008; 47(11):1443-1448.

21. Bragazzi NL, Bacigaluppi S, Robba C, Nardone R, Trinka E, Brigo F. Infodemiology of status epilepticus: A systematic validation of the Google Trends-based search queries. Epilepsy Behav 2016; 55:120-123.

22. Nghiem LTP, Papworth SK, Lim FKS, Carrasco LR. Analysis of the Capacity of Google Trends to Measure Interest in Conservation Topics and the Role of Online News. Gao Z-K, organizador. PLOS ONE 2016; 11(3):e0152802.

23. Schootman M, Toor A, Cavazos-Rehg P, Jeffe DB, McQueen A, Eberth J, Davidson NO. The utility of Google Trends data to examine interest in cancer screening. BMJ Open 2015; 5(6):e006678.

24. Toosi B, Kalia S. Seasonal and Geographic Patterns in Tanning Using Real-Time Data From Google Trends. JAMA Dermatol 2016; 152(2):215.

25. Troelstra SA, Bosdriesz JR, de Boer MR, Kunst AE. Effect of Tobacco Control Policies on Information Seeking for Smoking Cessation in the Netherlands: A Google Trends Study. PLOS ONE 2016; 11(2):e0148489.

26. Vasconcellos-Silva PR, Carvalho DBF, Trajano V, de La Rocque LR, Sawada ACMB, Juvanhol LL. Using Google Trends Data to Study Public Interest in Breast Cancer Screening in Brazil: Why Not a Pink February? JMIR Public Health Surveill 2017; 3(2):e17.

27. Ayers JW, Althouse BM, Noar SM, Cohen JE. Do celebrity cancer diagnoses promote primary cancer prevention? Prev Med 2014; 58:81-84.

28. Cooper CP, Gelb CA, Lobb K. Celebrity Appeal: Reaching Women to Promote Colorectal Cancer Screening. J Womens Health 2015; 24(3):169-173.

29. Dunlop K, Kirk J, Tucker K. In the wake of Angelina Managing a family history of breast cancer. Aust Fam Physician 2014; 43(1):76-78.

30. Juthe RH, Zaharchuk A, Wang C. Celebrity disclosures and information seeking: the case of Angelina Jolie. Genet Med 2015; 17(7):545-553.

31. Chiu TML, Eysenbach G. Theorizing the health service usage behavior of family caregivers: A qualitative study of an internet-based intervention. Int J Med Inf 2011; 80(11):754-764.

32. Eysenbach G. Infodemiology and Infoveillance. Am J Prev Med 2011; 40(5):S154-158.

33. Goel S, Hofman JM, Lahaie S, Pennock DM, Watts DJ. Predicting consumer behavior with Web search. Proc Natl Acad Sci 2010; 107(41):17486-17490.

34. Liu S, Dunford SD, Leung YW, Brooks D, Thomas SG, Eysenbach G, Nolan RP. Reducing Blood Pressure With Internet-Based Interventions: A Meta-analysis. Can J Cardiol 2013; 29(5):613-621.
35. Nolan RP, Payne AY, Ross H, White M, D'Antono B, Chan S, Barr SI, Gwadry-Sridhar F, Nigam A, Perreault S, Farkouh M, McDonald M, Goodman J, Thomas S, Zieroth S, Isaac D, Oh P, Rajda M, Chen M, Eysenbach G, Liu S, Zbib A. An Internet-Based Counseling Intervention With Email Reminders that Promotes Self-Care in Adults With Chronic Heart Failure: Randomized Controlled Trial Protocol. JMIR Res Protoc 2014; 3(1):e5.

36. Google. Google Trends [Internet]. 2017. [acessado 2017 Jan 10]. Disponível em: https://trends.google. com/trends/

37. Alexa. Top Sites in Brazil [Internet]. 2018. [acessado 2017 Jan 10]. Disponível em: https://www.alexa.com/ topsites/countries/BR

38. Sampaio LPB. Ketogenic diet for epilepsy treatment. Arq Neuropsiquiatr 2016; 74(10):842-848.

39. Kossoff EH, Doerrer SS, Turner Z. How do parents find out about the ketogenic diet? Epilepsy Behav 2012; 24(4):445-448.

40. Kossoff EH, McGrogan JR. Worldwide use of the ketogenic diet. Epilepsia 2005; 46(2):280-289.

41. Magrath G, MacDonald A, Whitehouse W. Dietary practices and use of the ketogenic diet in the UK. Seizure 2000; 9(2):128-130.

42. Vestir e maquiar. Dieta da lua [Internet]. 2015 [acessado 2017 Jan 10]. Disponível em: https://www.vestiremaquiar.com.br/dieta-da-lua/

43. Terra. Madonna segue dieta que promete eliminar 3

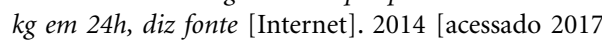
Jan 10]. Disponível em: https://saude.terra.com.br/ dietas/madonnasegue-dieta-que-promete-eliminar3-kg-em-24h-dizfonte,c22 bada65bec3410VgnVCM10000098cceb0aRCRD.html

44. Astrup A, Larsen TM, Harper A. Atkins and other low-carbohydrate diets: hoax or an effective tool for weight loss? Lancet 2004; 364(9437):897-899.

45. Mikkelsen PB, Toubro S, Astrup A. Effect of fat-reduced diets on 24-h energy expenditure: comparisons between animal protein, vegetable protein, and carbohydrate. Am J Clin Nutr 2000; 72(5):1135-1141.

46. Atkins RC. Dr. Atkins' new diet revolution. New York: Avon Books; 2002.

47. Ramos N. Mesmo magérrima, Bárbara Evans aposta na dieta que a fez perder $11 \mathrm{~kg}$ : Quando dá uma engordada, modelo apela para a dieta da proteína por uma semana. [Internet]. 2012 [acessado 2017 Jan 12]. Disponível em: http://entretenimento.r7.com/receitas-edietas/ noticias/mesmo-magerrima-barbara-evans-apostana-dieta-que-a-fez-perder-11kg20121109.html?question $=0$

48. Cavalheiro T. Dieta da proteina: enxuga 7 quilos em 14 dias: direto de Harvard, esta dieta sacode o metabolismo, fazendo você emagrecer até 7 quilos em 14 dias [Internet]. 2014 [acessado 2017 Nov 12]. Disponível em: https://boaforma.abril.com.br/dieta/dieta-da-proteina-enxuga-7-quilos-em-14-dias/

49. Aqui saudável. Sopa para emagrecer em 7 dias [Internet]. 2017 [acessado 2017 Nov 12]. Disponível em: http://www.aquisaudavel.com.br/sopa-para-emagrecer/

50. Zhu Y, Hollis JH. Soup Consumption Is Associated with a Reduced Risk of Overweight and Obesity but Not Metabolic Syndrome in US Adults: NHANES 2003-2006. PLoS ONE 2013; 8(9):e75630. 
51. Bertrais S, Galan P, Renault N, Zarebska M, Preziosi P, Hercberg S. Consumption of soup and nutritional intake in French adults: consequences for nutritional status. J Hum Nutr Diet 2001; 14(2):121-128.

52. Betoni F, Zanardo VPS, Geni GC. Avaliação de utilização de dietas da moda por pacientes de um ambulatório de especialidades em nutrição e suas implicações no metabolismo. ConScientiae 2010; 3:430-440.

53. Emagrecimento na saúde. A dieta dos pontos funciona de verdade? [Internet]. 2017 [acessado 2017 Jan 12]. Disponível em: https://emagrecimentonasaude.com/ dietas/dieta-dos-pontos/

54. Santana HMM, Mayer MB, Camargo KG. Avaliação da adequação nutricional das dietas para emagrecimento veiculadas pela internet. ConScientiae Saúde 2003; 2:99-104.

55. Klein AV, Kiat H. Detox diets for toxin elimination and weight management: a critical review of the evidence. J Hum Nutr Diet 2015; 28(6):675-686.

56. Allen J, Montalto M, Lovejoy J, Weber W. Detoxification in Naturopathic Medicine: A Survey. J Altern Complement Med 2011; 17(12):1175-1180.

57. Freeman TF, Willis B, Krywko DM. Acute intractable vomiting and severe ketoacidosis secondary to the Dukan Diet@. J Emerg Med 2014; 47(4):e109-112.

58. Wyka J, Malczyk E, Misiarz M, Zolotenka-Synowiec M, Calyniuk B, Baczynska S. Assessment of food intakes for women adopting the high protein Dukan diet. Rocz Panstw Zakl Hig 2015; 66(2):137-142.

59. Dieta Dukan. Método Dukan [Internet]. 2017 [acessado 2017 Dez 11]. Disponível em: http://www.dietadukan.com.br/metodo-dukan

60. Frozza F. Conheça a dieta Dukan, feita por Kate Middleton e Jennifer Lopez [Internet]. 2017 [acessado 2017 Dez 11]. Disponível em: https://www.terra.com. br/vida-eestilo/saude/dietas/conheca-a-dieta-dukanfeita-por-kate-middleton-e-jenniferlopez,dce73bb55005a310VgnVCM20000099cceb0aRCRD.html

61. Opie LH. Lifestyle and diet. Cardiovasc J Afr 2014; 25(6):298-301.

62. Marie Clarie. O carboidrato é vilão ou aliado?: Dra. Esthela Conde, especialista em nutrologia e nossa colunista, fala esta semana sobre carboidratos [Internet]. 2016. [acessado 2017 Out 1]. Disponível em: http://revistamarieclaire.globo.com/Beleza/noticia/2016/11/gordura-e-vila-ao-aliada.html

63. Farias SJSS, Fortes RC, Fazzio DMG. Análise da composição nutricional de dietas da moda divulgadas por revistas não científicas. Nutrire 2014; 39(2):196-202.

64. Moyad MA. Fad diets and obesity-Part IV: Low-carbohydrate vs. low-fat diets. Urol Nurs Off J Am Urol Assoc Allied 2005; 25(1):67-70.

65. Uol Notícias. Dieta paleolítica ajuda mulheres na menopausa, diz estudo [Internet]. 2016. [acessado 2017 Jan 13]. Disponível em: https://noticias.uol.com.br/ ultimasnoticias/ansa/2016/04/07/dieta-paleolitica-ajuda-mulheres-na-menopausa-diz-estudo.jhtm

66. Brasil. Ministério da Saúde (MS). Guia alimentar para a população brasileira [Internet]. Ministério da Saúde; 2014. [acessado 2017 Out 1]. Disponível em: http:// bvsms.saude.gov.br/bvs/publicacoes/guia_alimentar_ populacao_brasileira_2ed.pdf

67. Miranda AC, Minayo MCS. Saúde e ambiente sustentável: estreitando nós. Rio de Janeiro: SciELO Books Editora Fiocruz; 2002.
68. Castiel LD, Diaz CA-D. A saúde persecutória: os limites da responsabilidade. Rio de Janeiro: Fiocruz; 2012.

69. Contreras J, Gracia M. Alimentação, sociedade e cultura. Rio de Janeiro: Fiocruz; 2011.

70. Azevedo E. Riscos e controvérsias na construção social do conceito de alimento saudável: o caso da soja. Rev Saude Publica 2011; 45(4):781-788.

71. Kuwae CA, Carvalho MCVS, Prado SD, Ferreira FR. Concepções de alimentação saudável entre idosos na Universidade Aberta da Terceira Idade da UERJ: normas nutricionais, normas do corpo e normas do cotidiano. Rev Bras Geriatr E Gerontol 2015; 18(3):621630.

72. Habermas J, MacCarthy T, Habermas J. Lifeworld and system: a critique of functionalist reason. Boston: Beacon; 2005.

73. G1. Dieta da desintoxicação limpa nosso organismo e emagrece: Existem vários tipos de dietas desintoxicantes. A detox tradicional é sem lactose, sem glúten e sem proteina animal. Ou seja: nada de leite e derivados. [Internet]. 2013 [acessado 2017 Jan 13]. Disponível em: http:/g1.globo.com/globo-reporter/noticia/2013/11/ dietada-desintoxicacao-limpa-nosso-organismo-e-emagrece.html

74. G1. André Marques sobre cirurgia para emagrecer: "Eu ia morrer": Três meses e meio depois de fazer uma cirurgia de redução de estômago, o apresentador André Marques se prepara para a volta à TV. [Internet]. 2014. [acessado 2017 Jan 13]. Disponível em: http://g1.globo.com/fantastico/noticia/2014/03/andre-marquessobrecirurgia-para-emagrecer-eu-ia-morrer.html

75. Rayner G. Does celebrity involvement in public health campaigns deliver long term benefit? BMJ 2012; 345:e6364.

76. Baker JA, Lepley CJ, Krishnan S, Victory KS. Celebrities as Health Educators: Media Advocacy Guidelines. J Sch Health 1992; 62(9):433-435.

77. May ACW. Health campaigns entrench the role of celebrities in consumer marketing. BMJ 2012; 345:e6904.

78. Conrad P. The medicalization of society: on the transformation of human conditions into treatable disorders. Baltimore: Johns Hopkins University Press; 2007.

79. Viana MR, Neves AS, Camargo-Junior KR, Prado SD, Mendonça ALO. A racionalidade nutricional e sua influência na medicalização da comida no Brasil. Cien Saude Colet 2017; 22(2):447-56.

80. Mendonça ALO, Camargo-Júnior KR. O complexo médico industrial no contexto da comoditização da ciência: relativizando o relativismo. Rev Bras Ciênc Tecnol E Soc 2011; 2:7-31.

81. Bauman Z. Vida para consumo: a transformação das pessoas em mercadorias. Rio de Janeiro: Jorge Zahar; 2008.

Artigo apresentado em 12/04/2018

Aprovado em 16/10/2018

Versão final apresentada em 18/10/2018 
